\title{
Nacionalismo revolucionário e a política do discurso no México
}

Revolutionary Nationalism and the Politics of Discourse in Mexico Nacionalismo revolucionario y la politica del discurso en México

\author{
José Antonio Ferreira da Silva Júnior ${ }^{1 *}$ \\ ${ }^{1}$ Universidade Estadual de Campinas, São Paulo, Rio Brasil
}

SHEPPARD, R. A Persistent Revolution: History, Nationalism, and Politics in Mexico since 1968. Albuquerque: University of New Mexico Press, 2016. 392 p.

O México vem atraindo atençáo da grande mídia nos últimos tempos principalmente por sua relação cada vez mais delicada com os Estados Unidos. Após a eleição de Donald Trump (2016), o tema dos imigrantes ilegais e a construção de um muro na fronteira mexicana se tornaram tópicos recorrentes. $\mathrm{O}$ livro de Randall Sheppard, A Persistent Revolution (disponível on-line na plataforma Project Muse), é uma importante contribuição acadêmica a questóes que voltaram a surgir neste contexto e que demonstram como as análises da situação política mexicana ainda são parciais e enviesadas a partir do "poderoso vizinho do norte". O historiador da Universidade de Leiden, na Holanda, dedica-se a estudar as relaçôes entre política e história na construção do nacionalismo no México dominado pelo Partido Revolucionario Institucional (PRI), partido este que se construiu ao longo do século XX como o suposto herdeiro da Revolução Mexicana.

Esta não é a primeira publicação do autor sobre a história mexicana. O livro (SHEPPARD, 2016) é resultado de seu doutorado, conduzido na Univesidade La Trobe, na Austrália. Tendo passado por um pós-doutorado na Alemanha, em Colônia, entre 2013 e 2016, suas produções mostram-se dedicadas a estudar o México durante o século XX. Em dois artigos, analisou a dimensão discursivo-política em torno da crise econômica do México nos anos 1980 e a construçấo de um pavilhão dedicado ao país num parque temático do Walt Disney World. A Persistent Revolution, como trabalho de maior profundidade, permite a Sheppard pesquisar um período mais amplo e dar conta das transformaçóes que o discurso oficial do nacionalismo revolucionário sofreu ao longo de uma série de conjunturas políticas, econômicas e sociais durante o século XX e início do XXI.

Partindo de aportes teóricos consagrados, como os de Benedict Anderson e Eric Hobsbawm, em torno do nacionalismo, 
seus argumentos visam compreender como símbolos e mitos da história mexicana foram ressignificados conforme a necessidade do Estado priista e de atores políticos que buscaram legitimidade social no México. Dentre outras referências importantes para este livro estão os trabalhos de Mauricio Tenorio Trillo, historiador mexicano que atua na Universidade de Chicago. Esse autor destaca a importância do nacionalismo como categoria interpretativa da história mexicana. A obra de Claudio Lomnitz, antropólogo chileno da Universidade de Columbia, também é essencial para Sheppard interpretar e aplicar a teoria de Anderson sobre o nacionalismo na América Latina dos séculos XX e XXI. Além deles, os estudos de Ilene O’Malley, Thomas Benjamin, Samuel Brunk e Lynn Stephen são indicados como bibliografia básica no tema.

Segundo o autor, a construção e a consolidação do estado pós-revolucionário pelo PRI utilizou-se de mecanismos políticos e econômicos que pretendiam basear a sociedade em direitos coletivos adquiridos no processo revolucionário: as conquistas trabalhistas, a nacionalizaçáo do petróleo de 1938 e a reforma agrária são exemplos de como diferentes grupos foram setorizados na lógica corporativista da relação Estado-sociedade criada e fomentada pelo partido. Da mesma maneira, segundo Sheppard, mecanismos simbólicos foram essenciais nestes anos do século XX, neste período de construção do Estado-nação, para garantir a coesão social em torno do projeto nacional. Referências aos líderes do passado mexicano desde a independência da Espanha, em
1810, constituíram a principal forma de atribuir sentidos e significados às políticas pós-revolucionárias. No período de construção do Estado, entáo, teria ocorrido a consolidação de uma história nacional que narrava seus processos como momentos de ruptura capazes de estabelecer ou corrigir o percurso de desenvolvimento da nação. A Revolução do começo do XX, assim, foi vista como o "fim da história mexicana" (p. 59). O PRI erigiu-se como a manifestação da vontade da maioria da população que desejaria perpetuar suas conquistas e honrar as lutas daqueles heróis do passado que haviam se sacrificado para que o país atingisse tal momento.

A obra é dividida em seis capítulos que tratam de momentos políticos do país entre 1968 e 2012, investigando desde os usos da história pela política até campanhas eleitorais e resistências enfrentadas pelo PRI. Utilizando principalmente fontes oficiais, como pronunciamentos de líderes políticos em cerimônias cívicas, Sheppard analisa com cuidado a construção e o desenvolvimento do discurso nacionalista como orientador $\mathrm{da}$ ação política do governo mexicano.

Os capítulos seguem uma lógica temporal linear, entrelaçando temas políticos, econômicos e culturais com o contexto social do período em questão. Partindo da repressão violenta ao movimento estudantil no chamado Massacre de Tlatelolco (1968), o autor estuda como o presidente em exercício viu-se obrigado a enfrentar o descontentamento com o caráter autoritário que o Estado priista estava desenvolvendo. A partir de entáo, de acordo com Sheppard, todas as eleiçóes presidenciais foram momentos de reconstru- 
ção da identidade e relação entre povo e partido, entre sociedade e Estado, entre os mexicanos e o PRI. As crises internacionais do petróleo na década de 1970 e a consequente crise por conta da dívida externa, já nos anos 1980, indicaram o esgotamento do modelo político-econômico empreendido até então no país. As reformas neoliberais que começaram a ser definidas no governo de Miguel de la Madrid (1982-1988), e caracterizaram um intenso processo de modernização no governo de Carlos Salinas de Gortari (19881994), pautaram as maiores transformaçôes na lógica do nacionalismo revolucionário do PRI. Nesse contexto, o partido tinha de se sustentar como herdeiro da revoluçáo enquanto implementava medidas que desconstruíam conquistas sociais que por tantos anos mantiveram a legitimidade do partido no poder. Essa conjuntura dos anos 1980 e 1990, que tem um de seus pontos cruciais na assinatura do Tratado de Livre Comércio da América do Norte (Nafta), em 1994, é o foco principal do autor neste livro.

Em 2000, o PRI sofreu sua primeira derrota eleitoral na disputa pela presidência do México, chegando ao poder o conservador Partido Acción Nacional (PAN). Assim, Sheppard argumenta e analisa como a crise de representação que retirou o PRI do poder tem, na verdade, raízes mais profundas no modo como o Estado vinha lidando com as necessidades e as questóes sociais do país. Ao estudar os governos do PAN (2000-2012), fica claro que não houve uma ruptura com as práticas políticas do Estado priista. $\mathrm{O}$ autor demonstra que foi este entendimento que fez o povo mexicano optar nas eleiçôes de 2012 pelo candidato do PRI, agora com uma agenda renovada e estruturada em premissas distintas daquelas dos governos anteriores.

Cada capítulo é precedido por um breve texto introdutório que o autor chama de snapshot, uma descrição aproximada do contexto político e social do país em cada um dos momentos considerados chave para as transformaçóes e as reconfiguraçóes do nacionalismo revolucionário mexicano. Esses textos servem como uma boa estratégia que permite ao leitor náo especialista conhecer alguns detalhes de eventos que marcaram a história do país nos últimos anos. Dessa forma, Sheppard tem maior liberdade para abordar alguns acontecimentos, permitindo uma leitura mais fluida. Os capítulos, assim como os snapshots, trazem fotografias de alguns dos eventos mencionados que chamam atenção para a dimensão visual de monumentos, protestos, personagens e líderes.

A construção do discurso nacionalista, como estabelecem Anderson e Hobsbawm, passa também por apropriaçóes populares que se expressam por outros circuitos além dos discursos oficiais, revistas intelectuais e imprensa (principais fontes do autor). O livro, embora não contemple com igual atenção outras manifestaçôes populares, apresenta potencialidades: analisa movimentos sociais independentes ao PRI em protesto contra as diretrizes políticas impostas pelo Estado; elenca uma série de grupos que, longe de aceitar o nacionalismo revolucionário priista, criaram suas próprias dinâmicas de comunicação e construção identitária (sendo o mais representativo o neozapatismo dos 
anos 1990); e, por fim, indica como algumas minorias baseadas em identidades de diversidade cultural ou de gênero também se envolveram nos processos discutidos no livro. Novas pesquisas e trabalhos podem centrar-se nesses casos para analisar produçóes socioculturais que nos permitam observar como o nacionalismo e as identidades foram se constituindo em outros âmbitos da sociedade mexicana, além dos oficiais.

Esses temas de investigação já estão sendo explorados em obras como ;Viva la Historieta! Mexican comics, NAFTA, and the Politics of Globalization (University Press of Mississippi, 2009), de Bruce Campbell, que analisa histórias em quadrinho produzidas no contexto da modernização dos anos 1990 e da assinatura do Nafta. Outro livro neste sentido é Detonación: contra-cultura (menor) y el movimiento fanzine de Tijuana (19921994) (NortEstación Editorial, 2014), de Pedro Valderrama Villanueva, que apresenta um coletivo de produção cultural independente, no norte do México, num período em que o PAN ocupava o governo da Baja California pela primeira vez.

Com um estilo claro e simples, o texto de Sheppard permite uma leitura cadenciada mesmo para aqueles com um domínio intermediário da língua inglesa. A obra se destaca por ser o resultado de uma pesquisa intensa que renova os debates sobre o nacionalismo. Sua data de lançamento, no cenário político de eleiçôes presidenciais da América do Norte, se mostra oportuna, e suas contribuiçóes podem ser valiosas para uma perspectiva que entenda o México em suas especificidades históricas, políticas e culturais. A Persistent
Revolution é uma obra importante que traz discussóes em torno da história recente do México, esclarece como o discurso priista resolveu as aparentes contradiçôes entre neoliberalismo e Revolução no fim do XX e oferece uma competente interpretação do governo do PAN no início do século XXI.

\section{Referência bibliográfica}

SHEPPARD, R. A Persistent Revolution: History, Nationalism, and Politics in Mexico since 1968. Albuquerque: University of New Mexico Press, 2016. 392 p. 